Explaining Declining Educational Homogamy: The Role of Institutional Changes in Higher Education in Japan

Fumiya Uchikoshi, Department of Sociology and Office of Population Research, Princeton University, Princeton, NJ 08540.2626488750. uchikoshi@princeton.edu.

ORCID: 0000-0002-4972-4275

Running head: Explaining Declining Educational Homogamy in Japan

Word count: 9,070 words

An earlier version of this paper was presented at the RC28 summer meeting held at Princeton University on August 15-19, 2019. The Japanese Panel Survey of Consumers and the Keio Household Panel Study were provided by the Panel Data Research Center at Keio University. I thank several anonymous reviewers, Jim Raymo, Christine Schwartz, Eric Grodsky, Leafia Zi Ye, Kelsey Wright, Noah Hirschl, Sawako Shirahase, Sho Fujihara, Ryota Mugiyama, Kohei Toyonaga, Akira Igarashi, and seminar participants at the National Institute of Population and Social Security Research for their helpful comments and suggestions. This research is supported by the Nakajima Foundation and the Eunice Kennedy Shriver National Institute of Child Health \& Human Development of the National Institutes of Health under Award Number P2CHD047879. All errors are the author's own. 


\title{
Explaining Declining Educational Homogamy: The Role of Institutional Changes in Higher Education in Japan
}

\begin{abstract}
Research on educational assortative mating has devoted much attention to educational expansion but has been less focused on a concurrent trend of importance - growing differentiation among higher education institutions. In this study, I examine whether the bifurcation between high- and low-tier institutions in the context of high participation in tertiary education may help us understand the mixed evidence on educational homogamy trends across countries. Applying loglinear and log-multiplicative models to analyze trends in educational assortative mating in Japan, characterized by a clear and widely acknowledged hierarchy of institutional selectivity, I find that; (1) the odds of homogamy are higher among graduates of selective universities than among graduates of nonselective universities; (2) homogamy trends among graduates of selective and nonselective universities have diverged in recent years; (3) possibly reflecting the more rapid increase in the share of female students enrolled in less-selective institutions, the opportunity for them to "marry up" has decreased. Results suggest that close attention should be paid to the important and growing heterogeneity of institutional characteristics that has been obscured in earlier studies to understand the impact of educational assortative mating on economic inequality.
\end{abstract}

Key words: Marriage, Education, Assortative Mating, Japan 


\section{Introduction}

"Merely quantitative differences beyond a certain point pass into qualitative changes." Karl Marx, Capital: Volume One

The question of who marries whom is of great interest to demographers and stratification researchers. Research on assortative mating suggests that an increase in educational homogamy at the top of educational distribution may have potential impacts on economic inequality (Burtless 1999; Schwartz 2010) and intergenerational transmission of advantages (Breen and Andersen 2012; Breen and Salazar 2010; Esping-Andersen 2007; Torche 2010). Of particular theoretical interest to researchers has been how educational expansion affects educational homogamy trends (Blossfeld 2009; Kalmijn 1998; Schwartz 2013). Explanations vary, with some hypotheses predicting a positive influence of educational expansion (Blossfeld 2009; Blossfeld and Timm 2003; Kalmijn 1998; Mare 1991; Rauscher 2015) and others predicting the contrary (Smits 2003; Smits and Park 2009).

Empirical evidence on the impacts of educational expansion on educational homogamy is also inconsistent (Blossfeld 2009; Hout and DiPrete 2006). In absolute terms, as education expands and women come to outnumber men in higher education through educational expansion, educational hypergamy (women marrying up) is decreasing, while both homogamy and hypogamy (women marrying down) are increasing in many countries (Esteve et al. 2012, 2016; van Bavel et al. 2018). ${ }^{1}$ However, after controlling for compositional differences in educational attainment across time frames, evidence of relative trends in educational homogamy varies across countries (Hout and DiPrete 2006). ${ }^{2}$

\footnotetext{
${ }^{1}$ In the study of educational assortative mating, higher education is typically a single category that lumps all types of four-year (and higher) tertiary education together.

${ }^{2}$ Using simple categorical measures of education, prior studies have two ways of measuring educational assortative mating: one is the overall prevalence of different types of pairings, while the other is the relative likelihood of different pairings net of marginal distributions. The current study focuses on the second type of measure.
} 
This paper argues that those studies have missed one important mechanism, that is, the growth in institutional heterogeneity. Prior studies have argued that the quantitative change in higher education has transformed the qualitative aspects of higher education. Specifically, education expansion is accompanied by a growth of institutional heterogeneity through the proliferation of lower-tier institutions (Arum et al. 2007; Hoxby 2009). The impacts of the growth of institutional heterogeneity could be driven by two mechanisms. First, it could be driven by a compositional process, where the baseline odds of homogamy may differ for graduates of lower-tier institutions and those of higher-tier ones, while the relative distribution of these graduates has changed over time. Specifically, the former may be more likely to marry noncollege graduates than are members of the most selective group, who by contrast are more likely to marry graduates of equally selective educational institutions (Arum et al. 2008). If so, the increase in the number of graduates of lower-tier institutions may decrease the odds of homogamy among college graduates if no compositional adjustment is made. Second, it could be driven by a diverging process, where the odds of homogamy for lower-tier and higher-tier graduates have changed over time, net of the compositional changes. Specifically, this mechanism posits that if the boundary between selective and less-selective groups has intensified with the increase in the number of lower-tier institutions, then recent cohorts of these graduates of selective universities may be increasingly more likely to marry selective college graduates. ${ }^{3}$ If correct, this contributes to mitigating the decline in educational homogamy.

This study is motivated by the concern that ignoring the growth of within-group variation in higher education may prevent the accurate evaluation of educational assortative mating trends. Although previous studies mentioned this growth as a likely explanation of current educational homogamy trends (Arum et al. 2008; Hersch 2013; Schwartz and Mare

\footnotetext{
${ }^{3}$ Arum and Roksa (2014) defined college selectivity in the U.S. based on the SAT percentile scores of college entrants. The university hierarchy in Japan, which I examine in this paper, also reflects the difficulty of entrance examinations (Ishida 2007), but institutions that require higher entrance examination scores are often historically prestigious ones. Therefore, selectivity measures based on entrance examinations and institutional prestige are highly correlated, and in this paper I use selectivity.
} 
2005), they did not evaluate this possibility by explicitly modeling the implications of the growing differentiation in higher education for assortative mating trends. A focus on the growing heterogeneity among university graduates in terms of their institutional selectivity could help us to understand the mixed evidence on the trends in educational homogamy across countries and provide new insights into the potential role of educational assortative mating for stratification and inequality.

Another focus of this paper is on relative gender difference in the rate of expansion. While previous studies have assumed that the odds of educational homogamy net of compositional changes are less affected by the different rate of expansion by gender, the odds of marrying homogamously are not just a function of the size of one's education group but also a function of the relative proportions of both males and females with one's level of education. This suggests that taking into account not just expansion of higher education but gender differentials in rates of expansion is critical for understanding the putative role of educational expansion in generating trends in educational homogamy. The current study answers this question by explicitly examining female hypergamy patterns within university education.

The current study examines Japan as an interesting case of potentially broader relevance to other societies because of its clear and widely acknowledged selectivity-based hierarchy of higher education institutions. Japan is one of the countries where educational homogamy has declined continuously since the 1950s (Fujihara and Uchikoshi 2019; Fukuda et al. 2021; Miwa 2007). Increased postsecondary educational attainment in Japan has been promoted through the growth of private institutions, including upgrades of private junior colleges, which are seen as lower in the hierarchy of selectivity (Ishida 2007). If this increasing share of private universities has reduced the relative value of tertiary education in the marriage market in Japan, graduates of these institutions may be increasingly likely to marry nongraduates, as one recent study speculated this might be the case (Fukuda et al. 2020). ${ }^{4}$

\footnotetext{
${ }^{4}$ The author is aware that the younger cohorts in Japan are marrying later and less. It could be also the case that patterns of educational assortative mating may be influenced by the trend toward later and less marriage.
} 
Thus, the current study addresses three questions. First, I ask whether the strength of homogamy among university graduates differs depending on the selectivity of the institution they attended. I hypothesize that educational homogamy is stronger for the most selective group and less pronounced for the other, less selective groups. Second, after confirming the previously documented decline in homogamy among university graduates, I examine the extent to which the declining trend reflects a combination of the compositional shift, especially among graduates of lower-tier institutions, and an increasing likelihood of homogamy among selective college graduates. Third, I evaluate the potential role of relative gender difference in the rate of higher education by examining the persistence of female educational hypergamy within university education.

This study contributes to updating the general implications of educational assortative mating for stratification research. Specifically, results of this study imply that the mechanism behind educational assortative mating trends in Japan may also operate in other contexts where educational expansion is characterized by stratification in higher education through the growth of lower-tier institutions (Hoxby 2009; Roksa et al. 2007). This study also provides important insights into the potential role of horizontal stratification in contemporary societies (Gerber and Cheung 2008), where as an increasing number of individuals enter higher education in many countries, simply looking at the vertical aspects of educational attainment obscures a potentially important source of inequality.

\section{Background}

\section{The role of expansion and differentiation in higher education institutions}

Studies have revealed that changes in educational assortative mating depend on how institutional contexts influence preferences and the opportunity structure in the marriage market (e.g., Blossfeld and Timm 2003; Rauscher 2015), two components influencing who marries whom

While they are all interesting and important, these aspects are not directly relevant to the analyses of educational pairing conditional on marriage. 
(Kalmijn 1998). Among the possible institutional mechanisms, educational expansion is particularly relevant. While the theoretical expectations of prior studies are varied, they have all assumed that increased access to higher education occurs uniformly. The limited focus on the quantitative increase in the number of highly educated individuals (which I call expansion) may obscure another important mechanism that influences the pattern of educational assortative mating, that is, the growth of variation within higher education (which I call institutional differentiation) (Arum et al. 2007).

Both opportunity structure and preference perspectives have hypothesized educational expansion can increase educational homogamy. On the one hand, structural theory (Blau and Schwartz 1984), which focuses on the role of opportunity structure, explicitly posits that educational expansion increases homogamy, especially among the highly educated, because such expansion increases the possibility of meeting equally educated spouses at the ages when marriage is most likely to occur (Blossfeld 2009; Mare 1991). On the other hand, preferencebased hypotheses also predict that educational expansion leads to increased homogamy. Schwartz and Mare (2005), for example, posited that potential spouse's preferences for partners have become more symmetric over time as a result of women's increasing education and earning potential (Oppenheimer 1988). Both hypotheses have been supported with data from many contexts (Han 2010; Hu and Qian 2015; Ravazzini et al. 2017; Wong 2003).

Meanwhile, Smits (2003) and Smits and Park (2009) predict an opposite consequence of educational expansion. According to what they call the exclusivity hypothesis, educational homogamy among college graduates is stronger when their group size is smaller. The rationale for this prediction comes from the theory of status closure or status-group credentialism (Collins 1979), which posits that elite small groups are aware of their advantages. This awareness may increase these groups' motivation to maintain the social boundary and exclude outgroups (Parkin 1971). If group size increases, however, the relative value of higher education decreases, and barriers to mating with members of elite groups should also decrease. Therefore, this hypothesis predicts that educational expansion promotes intermarriage between educational elites and 
others. The decline in educational assortative mating in several countries, including Japan (Fujihara and Uchikoshi 2019; Fukuda et al. 2021; Miwa 2007), France (Bouchet-Valat 2014), Denmark (Andrade and Thomsen 2018), and Eastern Europe (Katrňák and Manea 2020) and East Asia (Smits and Park 2009), fits with this theoretical expectation.

The exclusivity hypothesis better aligns with the perspective in this study on the cooccurrence of expansion and differentiation in the sense that this hypothesis predicts that a quantitative increase in group size is accompanied by qualitative changes in the value of higher education in the marriage market; however, even this hypothesis does not consider the likely heterogeneity among university graduates. The distinction between expansion and differentiation provides important insights, especially when the increase in the number of people with higher education is promoted through the growth of less selective institutions (Arum et al. 2007: 5). Although they only indirectly address the topic, a few studies have argued that college selectivity is associated with marrying spouses from postsecondary institutions with similar academic selectivity (Arum et al. 2008; Feng 2022; Uchikoshi and Raymo 2021). These results suggest that graduates of selective institutions are more likely to seek college graduates of similarly ranked institutions to maintain social boundaries, which is consistent with the exclusivity hypothesis.

Arguably, the distinction between educational expansion and differentiation within higher education is not new in social stratification research. In particular, the effectively maintained inequality (EMI) hypothesis provides relevant insights into my research question. This hypothesis proposed by Lucas (2001) posits that educational inequality is maintained even when vertical inequality in educational attainment decreases through improved access to higher education because privileged groups seek qualitative advantages within a given level of education to maintain their positions. ${ }^{5}$ Applying this perspective, we can expect that to the

\footnotetext{
5 Attempts to link the EMI hypothesis to educational assortative mating are not new, as Andrade and Thomsen (2018) mentioned an impact of differentiation in higher education on assortative mating, but their focus was more on diversification of fields of study.
} 
extent that the importance of selectivity within higher education is constant or increases in tandem with the increase in the number of lower-tier private institutions in Japan, the strength of homogamy among graduates of selective universities may increase.

Importantly, these theories have not adequately discussed the potential role of relative gender difference in higher education expansion, while in reality it is often the case that trends in access to higher education differ for men and women (DiPrete and Buchmann 2013; Esteve et al. 2012). The gender gap in educational expansion has a direct influence on the absolute rate of educational assortative mating, such as the increasing prevalence of educational hypogamy (Esteve et al. 2012; van Bavel et al. 2018), while this also plays a critical role for the relative odds of educational homogamy. For example, suppose there are 100 men and 100 women with university education. If we increase the total number of university graduates by 100 for men and zero for women, this means that there are fewer women per man with university degrees. Therefore, it is impossible for homogamy to increase under such circumstances because at most half of the men with university degrees can marry similarly educated women. This simple example shows how important it is to consider not only higher education expansion, but relative gender differences in rates of expansion. As I discuss below, this perspective is critical for understanding educational assortative mating in Japan characterized by strong preference for female hypergamy (Brinton et al. 2021; Raymo and Iwasawa 2005).

\section{The Japanese context}

\section{Trends in educational assortative mating}

Much evidence suggests that educational homogamy has declined in Japan (Fujihara and Uchikoshi 2019; Fukuda et al. 2021; Miwa 2007). The overall odds of homogamy, for example, decreased by approximately 25\% between the 1950-1954 and the 1975-1979 birth cohorts (Fujihara and Uchikoshi 2019). Unfortunately, these studies also treated university degrees and their granting institutions as homogeneous, which limits our understanding of the plausible impacts of the growing heterogeneity in higher education on assortative mating. Importantly, 
however, a few studies suggested that a closer look at the growth in heterogeneity within higher education provides important insights into the decline in educational assortative mating in Japan. Japan has been characterized by the social norm that encourages women to prefer "marrying up" (female hypergamy) (Brinton et al. 2021; Raymo and Iwasawa 2005). This hypergamy norm was rooted in gender-inegalitarian social regimes in which women's socio-economic status was systematically lower than men's. In contrast to the well-established knowledge, Fukuda et al. (2020) found an increase in educational hypogamy among university-educated women who married between 1990 and 2013. They interpreted this could suggest "the social and economic boundaries between lower-ranked universities and technical colleges may be declining among younger cohorts" (Fukuda et al. 2020: 1393).

\section{An overview of the higher education system}

Japanese universities are characterized by their position within a clear and widely acknowledged hierarchy of institutional selectivity (Yonezawa et al. 2002). ${ }^{6}$ National/public universities are often perceived to be more selective and of better quality, while private universities (with a few notable, widely recognized exceptions) are generally thought to be in a lower tier (Ishida 1998; Ono 2008). Importantly, an increase in the number of private institutions has meant a larger share of graduates of these less selective universities within the pool of college graduates.

Figure 1 illustrates two stages of educational expansion and upgrades of junior colleges into four-year universities, which contributed to the growing institutional selectivity. This figure presents trends in (1) male and female entrance rates to four-year universities (including national, public, and private, calculated by the total number of enrolled students out of high school

\footnotetext{
${ }^{6}$ According to Times Higher Education's Japan University Rankings 2022 (https://japanuniversityrankings.jp/rankings/), ten out of the top 10, 36 of the top 50, and 70 of the top 100 universities are national or public institutions. Since national or public universities account for less than $25 \%$ of all four-year universities, the overrepresentation of these universities in the ranking supports the claim that national or public universities are perceived to be more selective.
} 
graduates) and (2) the proportion of students enrolled in private universities by gender. During the first stage of private university expansion, from the late 1950 s to the late 1970 s, the proportion of students enrolled in private universities continuously increased for both men and women. This expansion was driven by newly established private institutions, which are mostly located in the lower ranks of the hierarchy of selectivity (Ishida 2007). The absolute and relative increases in the representation of students from these lower-tier private universities thus drove the growth in heterogeneity among university students. This trend continued during the second stage of expansion, which was also implemented through the establishment of new private universities. As Figure 1 shows, although the proportion of students enrolled in private institutions slightly decreased during this period, it has been stable since 1995. As in the first stage of expansion, the private universities that contributed to the expansion of higher education are still considered less selective (Ishida 2007).

[Figure 1 is about here]

The upgrade of junior colleges into private universities is another mechanism through which heterogeneity across universities in Japan has grown. According to government statistics (MEXT 2019), junior colleges are mostly established by private institutions (84\% as of 1995) and are frequently characterized by a high concentration of female students (almost $90 \%$ of the students enrolled in junior colleges from the 1980s). As women's opportunities to enter occupational careers increased, female students began to aim for a four-year university (Edwards and Pasquale 2003). Suffering from a shortage of applicants, many private junior colleges decided to upgrade into four-year universities. As a result, the number of junior colleges thus decreased from 596 to 337, while that of private four-year universities increased from 415 to 604 between 1995 and 2017 (MEXT 2019). Importantly, these upgraded institutions have been less selective in recruiting students, suggesting that private institutions have become increasingly heterogeneous in terms of school selectivity. 
To summarize, we can expect that that men and women in Japan have experienced educational expansion differently, not only in terms of the timing of expansion but also the selectivity of colleges they attended. This education context leads to the value to explicitly examine a potential heterogeneity in gender difference in spouse pairing patterns within university education, which in turn helps us to understand the role of educational expansion for assortative mating trends. Specifically, the more rapid increase in the proportion of female students enrolled in private institutions than male students suggests that the relative value of higher education has become more heterogeneous for the former. If the growing heterogeneity is accompanied by an increase in lower-tier private university graduates, female private university graduates would be increasingly less likely to marry up with male national/public university graduates in recent years.

\section{Research questions and hypotheses}

While the importance of horizontal stratification in higher education has been emphasized in the social stratification literature, consideration of how this factor impacts educational assortative mating has been limited. By linking the growing institutional heterogeneity at the top of educational distribution to the core of the stratification analytical framework, this study updates our understanding of the educational assortative mating trend.

A focus on institutional differentiation in higher education provides several testable hypotheses to explain declining educational homogamy in Japan. Specifically, I test five hypotheses. While the first two hypotheses are related to patterns of assortative mating, the last three hypotheses examine temporal trends of assortative mating. Note that all the hypothesis tests are based on estimates conditional on the composition of relevant characteristics (educational attainment and cohorts for Hypotheses 1 and 2, and educational attainment for Hypotheses 3, 4 and 5).

First, drawing on the exclusivity hypothesis, Hypothesis 1 expects that the strength of homogamy among university graduates differs by the selectivity of their institutions. 
Specifically, I hypothesize educational homogamy is stronger for the most selective group (national and public university) but to be less pronounced among less selective groups (private university). If supported, this would suggest that educational homogamy among university graduates has declined partly because of the increase in the number of graduates of less selective universities in recent years.

Hypothesis 1: The odds of homogamy are strongest for national and public university graduates but lower for those attending a private university.

Second, relatedly, the presence of preference for female hypergamy (Brinton et al. 2021; Raymo and Iwasawa 2005) allows us to expect that we might see a similar hypergamy pattern within university education. Specifically, Hypothesis 2 expects that the relative likelihood of women marrying up (hypergamy, in terms of college selectivity) is higher than that of women marrying down (hypogamy).

Hypothesis 2: The odds of female hypergamy are stronger than female hypogamy within university education.

Next, I test whether distinguishing between university graduates based on their institutional selectivity explains the decline in educational assortative mating in Japan. Specifically, I test whether the direction of change in assortative mating differs by university selectivity.

Hypothesis 3a: The association of educational attainment between spouses increases among national/public university graduates. 
Hypothesis 3b: The likelihood of marrying national/public university graduates decreases over cohorts among private university graduates.

Last, I test whether the female hypergamy pattern within university education, especially female private university graduates marrying up national/public university graduates, has declined. This could happen because of the compositional mechanism, as the proportion of students enrolled in private universities has increased more rapidly for women than men. Meanwhile, as the exclusivity hypothesis expects, it could be the case that in response to the numerical increase in less-selective college graduates, selective college graduates may maintain their advantaged status via marriage. In either case, female less selective college graduates are increasingly less likely to marry up.

Hypothesis 4: The likelihood of educational hypergamy between female private university graduates and male national/public university graduates decreases.

\section{Data and method}

\section{Data}

This study used all the available years for two comparable panel surveys: the Japanese Panel Survey of Consumers (JPSC) and the Keio Household Panel Study (KHPS). One reason for the lack of consideration of institutional differentiation in previous literature is data limitations. Most surveys do not ask about the characteristics of the spouse's college (Arum et al. 2008: 110; but see Andrade and Thomsen 2018 for a recent exception). By contrast, the JPSC and KHPS collect information about the types of schools from which both respondents and their spouses graduated. I combined these two data to increase the sample size.

JPSC and KHPS are highly comparative from design to implementation. In terms of sampling strategy, they employed the same sampling technique (a standard stratified two-stage sampling where the first stage is based on census areas and the second stage is to randomly 
sample about 10 individuals in each census area). Importantly, in both surveys, the fieldwork was conducted by the same agency, i.e., Central Research Services (Chuo Chosasya). Moreover, the initial response rate is almost equal (41.4\% for JPSC and $41.1 \%$ for KHPS) (Ishii and Nozaki 2014; Sakaguchi 2014), although the retention rates are slightly higher for JPSC ( $94.4 \%$ to 98.3\% for JPSC versus $82.7 \%$ to $94.2 \%$ for KHPS). Therefore, in this study I pooled the two samples to form a single data file by extracting information on gender, year of marriage, respondent's and spouse's education. ${ }^{7}$ To make the sample representative to the national population, I constructed the cross-sectional and longitudinal weights. Estimated results are based on the weighted sample (see details for how to construct the weights in Appendix).

The 1993 JPSC was the first nationally representative longitudinal survey in Japan to target young women (aged 24 to 34) and continues to be conducted annually. Later waves (1997, 2003, 2008, and 2013) added additional cohorts of women aged mid to late 20 s. The first wave of the KHPS was in 2004; respondents in the first wave were from a nationally representative sample of 4,000 households. A total of 1,400 households were added in 2007 and 2012. Reflecting the growing privacy concerns in recent years, the retention rate is lower for the KHPS than the JPSC, but the rate is comparable to other well-recognized panel studies (e.g. PSID or SIPP) (Naoi 2006). ${ }^{8}$

\section{Variables}

I use five categories for the husband's and wife's educational attainment: $1=$ high school or less, including junior high school, 2 = junior college, college of technology, or professional training college, 3 = private university, and $4=$ national or public university.

\footnotetext{
${ }^{7}$ I estimated log-linear models separately for JPSC and KHPS sample. Appendix Figures 1 and 2 are the replication of Figure 4 in the main text. Substantively, these estimates are comparable.

8 Specifically in my study, the retention could be a problem if there is any selective attrition by their education characteristics, because I used the information about spouse's education respondents answered after they married, if they were not married at the time of the first interview. I discuss these points in Appendix.
} 
Given my focus on exclusivity and institutional differentiation, this study does not consider educational attainment beyond an undergraduate university degree. In my sample of university graduates, some respondents also obtained Master's or PhD degrees (1.5\%). Although the study of such educational attainment is important, I use only these respondents' undergraduate degree in my analysis. For respondents' education, I use the information at the time of the first interview. For spouses' education, I use the information at the time of the first interview if respondents were already married. If not, I use the information provided after they married.

After I omit cases with missing educational information, 7,434 couples remain $(2,685$ cases for the JPSC and 4,749 cases for the KHPS). The year of marriage ranges from 1954 to 2015 in this sample. For the purpose of this study on the impact of expansion and institutional differentiation in higher education, to minimize the possibility that respondents and their spouse graduated before the education system reform after WWII, I limit the sample to respondents who married from 1970 to 2015 , resulting in the removal of $12 \%$ of the observations. ${ }^{9}$ I then divide the sample into 15-year marriage cohorts (1970-1984, 1985-1999, and 2000-2015). The division between the late 1990s and early 2000s is critical to this study, as a number of junior colleges upgraded into four-year private universities in this period as discussed above, likely contributing to the growth in heterogeneity among four-year universities.

\section{Method}

Assortative mating is formed through at least two mechanisms, preference and opportunity (Kalmijn 1998). Since the observed marriage patterns include the contribution of each mechanism, without an appropriate method one could not distinguish each other to discuss which factor contributes to the rise of decline in a given marriage pattern like educational homogamy.

\footnotetext{
${ }^{9}$ Unfortunately, these surveys do not distinguish first from later marriages. As the prevalence of remarried couples has increased in Japan, the inability to distinguish them from the first-married population may induce biased results.
} 
The current study is interested in educational homogamy net of marginal distributions of men's and women's educational attainment. This means that I control for compositional changes in educational attainment between men and women. I then examine changes in the odds ratio of homogamy conditional on educational attainment distributions.

To capture these odds ratios and their changes, which is assumed to capture preference, ${ }^{10}$ I apply log-linear and log-multiplicative models. This has been the "gold standard" to describe patterns and trends in assortative mating (Lichter and Qian 2019 for a methodological review). Suppose we apply this method to three-way tables of the husband's educational attainment $H(i=1, \ldots, 4)$, the wife's educational attainment $W(j=1, \ldots, 4)$, and the respondent's marriage cohort $C(k=1, \ldots, 3)$, The baseline model is the conditional independence model, which assumes the independence of wives' and husbands' education:

$$
\ln F_{i j k}=\lambda+\lambda_{i}^{H}+\lambda_{j}^{W}+\lambda_{k}^{C}+\lambda_{i k}^{H C}+\lambda_{j k}^{W C}
$$

(Model 0)

where $F_{i j k}$ is the expected frequency of the $(i, j, k)$ cell, consisting of husbands with education $i$ and wives with education $j$ who married in cohort $k .^{11} \mathrm{I}$ set this model as the baseline and expand upon it by adding other parameters. Each value for education and cohort corresponds to the categories that I defined previously. For example, $F_{433}$ indicates the frequency of couples in which the husbands are national/public university graduates, the wives are private university graduates, and the marriage occurred in a year in the period 2000-2015.

Based on this model, I examine various extensions to test my hypotheses. First, Model 1a represents the quasi-independence model of homogamy:

10 But see there is some critique against this interpretation (Logan 1996).

11 Although not expressed here, all the models include category $l$, where the cell is distinguished by whether it comes from JPSC or KHPS. 


$$
\ln F_{i j k}=\lambda+\lambda_{i}^{H}+\lambda_{j}^{W}+\lambda_{k}^{C}+\lambda_{i k}^{H C}+\lambda_{j k}^{W C}+\delta_{i j}^{H W} \text {, where } \delta_{i j}^{H W} \text { follows matrix } 1 .
$$

(Model 1a: Homogamy)

This model estimates the likelihood of homogamy that is consistent across education levels. ${ }^{12}$ The model also treats marriage between all university graduates equally regardless of the selectivity of their institutions. To fit a different parameter for each cell, I use design matrices (shown in Appendix Table 1). Design matrix for Model 1a, for example, corresponds to Matrix 1, where homogamy among high school graduates or less is expressed as 1 while university homogamy is expressed as 2 , as compared with the reference $(0$, other types of assortative mating).

Next, to capture a gradient in the odds of homogamy based on institutional selectivity, I estimate four models ( $1 \mathrm{~b}$ to $1 \mathrm{~d})$ to test Hypothesis 1 . Model $1 \mathrm{~b}$ assumes distinct diagonal parameters among university graduates but treats off-diagonal cells among graduates equally (see matrix 2 in Appendix Table 1), and Model 1c captures the strength of the association for each cell on the main diagonal in comparison to that for the off-diagonal cells (see matrix 3 in Appendix Table 1).

While these models, including Model 1a, examine homogamy within educational groups, Model 1d reflects the permeability of barriers to marriage across educational types between spouses. The equation is defined as follows:

$$
\ln F_{i j k}=\lambda+\lambda_{i}^{H}+\lambda_{j}^{W}+\lambda_{k}^{C}+\lambda_{i k}^{H C}+\lambda_{j k}^{W C}+\gamma_{i j}^{H W}
$$

where $\gamma_{i j}^{H W}=\sum_{q=j}^{i-1} \gamma_{q}$ for $i>j, \gamma_{i j}^{H W}=\sum_{q=i}^{j-1} \gamma_{q}$ for $i<j$, and $\gamma_{i j}^{H W}=0$ for $i=j$.

(Model 1d: Crossing)

\footnotetext{
12 It should be noted that these parameters do not capture homogamy among junior college graduates, because prior work argued that trends in homogamy among junior college graduates are stable (Fujihara and Uchikoshi 2019). As the aim of this study is to explain the declining trends in educational homogamy, I did not consider their homogamy in analysis.
} 
This parameter is additive, and so for example, the odds ratio of husbands with a national/public university education crossing barriers and marrying wives with a junior college education is $\gamma_{42}^{H W}=\gamma_{2}+\gamma_{3}$

When I discuss the model fit for these models, I also reference the saturated model. This model provides us with a reference for selecting the best-fitting models, as models with better fit statistics than that of the saturated model are able to capture the association more parsimoniously. The equation for the saturated model is as follows:

$$
\ln F_{i j k}=\lambda+\lambda_{i}^{H}+\lambda_{j}^{W}+\lambda_{k}^{C}+\lambda_{i k}^{H C}+\lambda_{j k}^{W C}+\psi_{i j}^{H W}
$$

Model 2 is used to test Hypothesis 2 (the persistence of female hypergamy), which relaxes the quasi-symmetry assumption that characterizes the off-diagonal parameters in Model 1b (see matrix 4 in Appendix Table 1).

Next, I examine whether the degree of educational assortative mating varies by marriage cohort. To investigate the trends in educational assortative mating, I estimate Model 3a based on Schwartz and Mare (2005):

$$
\begin{array}{r}
\ln F_{i j k}=\lambda+\lambda_{i}^{H}+\lambda_{j}^{W}+\lambda_{k}^{C}+\lambda_{i k}^{H C}+\lambda_{j k}^{W C}+\lambda_{i j}^{H W}+\delta_{i j k}^{H W C}, \\
\text { (Mhere } \delta_{i j k}^{H W C} \text { follows matrix } 1 . \\
\text { (Model 3a: Changing homogamy) }
\end{array}
$$

I also apply the log-multiplicative layer effects models (Xie 1992), which allows me to estimate changes in the strength of the associations over time while assuming that the overall patterns are constant:

$$
\ln F_{i j k}=\lambda+\lambda_{i}^{H}+\lambda_{j}^{W}+\lambda_{k}^{C}+\lambda_{i k}^{H C}+\lambda_{j k}^{W C}+\beta_{k}^{C} \delta_{i j}^{H W} \text {, where } \delta_{i j}^{H W} \text { follows matrix } 1 .
$$

(Model 3b: Homogamy, Log-multiplicative) 
Here, $\delta_{i j}^{H W}$ indicates the homogamous association between wives' and husbands' educational achievement and $\beta_{k}^{C}$ is the log-multiplicative parameter. This model produces a parsimonious estimation of changes in the strength of the association with flexibility in specifying the association (Xie 1992). The $\beta$ parameter is set to 1 , with the oldest cohort as the reference, and I evaluate changes in the association in terms of the percent change in this parameter relative to the value for the reference cohort.

To test Hypothesis 3 (increasing odds of homogamy among selective college graduates and decreasing likelihood of less selective college graduates marrying selective college graduates), I apply Models 3c to 3e. All of these models are either changing homogamy or crossing models based on the models used to test Hypothesis 1. For example, Model 3c is expressed as follows:

$$
\begin{array}{r}
\ln F_{i j k}=\lambda+\lambda_{i}^{H}+\lambda_{j}^{W}+\lambda_{k}^{C}+\lambda_{i k}^{H C}+\lambda_{j k}^{W C}+\lambda_{i j}^{H W}+\delta_{i j k}^{H W C}, \text { where } \delta_{i j k}^{H W C} \text { follows matrix } 2 . \\
\text { (Model 3c: Changing homogamy) }
\end{array}
$$

Last, to test Hypothesis 4 (changes in the strength of female educational hypergamy), I apply Model 4 which uses the same design matrices examined in Model 2. Specifically, this model is expressed as follows.

$$
\ln F_{i j k}=\lambda+\lambda_{i}^{H}+\lambda_{j}^{W}+\lambda_{k}^{C}+\lambda_{i k}^{H C}+\lambda_{j k}^{W C}+\lambda_{i j}^{H W}+\delta_{i j k}^{H W C} \text {, where } \delta_{i j k}^{H W C} \text { follows matrix } 4 .
$$

(Model 4: Changing female hypergamy)

\section{Results}

\section{Descriptive results}

Figure 2 shows the distributions of educational attainment for married men and women separately using the JPSC and KHPS. Both men and women in recent marriage cohorts are more likely to complete four-year universities than those in previous marriage cohorts. Despite the general rise in educational attainment among women, gender differences in educational 
attainment persist among recent cohorts. In terms of heterogeneity by university selectivity, the proportion of national/public university graduates remains largely the same across cohorts, while the proportion of private institution graduates increases. This is consistent with the fact that women's access to higher education has been promoted through an increase in the number of private institutions, including schools upgraded from junior colleges.

[Figure 2 is about here]

Figure 3 presents changes in the observed proportions of educational homogamy, female hypergamy, and female hypogamy on the left and the expected proportions, which are calculated under the assumption that the husband's and wife's education levels are independent of each other, on the right. Within the observed proportions, 48\% of marriages in the 1970-1984 cohort are homogamous, and homogamy still characterizes more than $37 \%$ of the latest cohort. In contrast, both educational hypergamy and educational hypogamy slightly increase from the oldest cohort to the latest cohort. The expected proportions (right) show trends similar to those in the observed proportions. The proportion of homogamy decreases, while we see the increasing trend for hypergamy and hypogamy. This result suggests that the observed trends are largely due to changes in the marginal distributions of men's and women's educational attainment. One interesting finding is that expected educational homogamy is lower than the observed rate. Intuitively, it is plausible that educational expansion could lead to an increase in educational homogamy as the distributions of men's and women's education become more similar. However, the figure shows that this is not the case in Japan, which is not surprising in light of the previous studies cited above.

[Figure 3 is about here]

\section{Log-linear and log-multiplicative models}


To investigate the relative association between wives' and husbands' educational attainment, I estimated log-linear and log-multiplicative layer effects models. Table 1 provides the goodnessof-fit statistics for the models: the log-likelihood ratio chi-squared statistic $\left(G^{2}\right)$, the degrees of freedom (df), the index of dissimilarity $(I D)$, and the Bayesian information criterion $(B I C) .{ }^{13}$ The $I D$ is the proportion of misclassified cases in a given model. Thus, the smaller the $I D$, the better is the model fit. The $B I C$ adds a penalty for the number of parameters related to $G^{2}$ in a given model, so the more negative the $B I C$, the better is the model fit. One advantage of referring to the $B I C$ is that for a fully saturated model, this criterion should be 0 (Raftery 1995). Thus, it is expected that models with a $B I C$ lower than 0 are preferred over models with a positive $B I C$. Throughout the analysis, I prioritize the $B I C$ whereas refer to the $I D$ for a descriptive purpose.

[Table 1 is about here]

Assortative mating patterns within university education

Model 0 (conditional independence) shows that $19 \%$ of cases are misclassified in this model. Model 1a adds homogamy parameters, which improve the model fit compared with that of Model 0 . Models $1 \mathrm{~b}$ to $1 \mathrm{~d}$ are estimated to test Hypothesis 1 . Among the two homogamy models, Model 1b which uses matrix 2, where I define homogamous marriages as the association in each cell on the main diagonal above college education ( 3 and 5), while treating the offdiagonal associations among university graduates as a separate group (4), is the best fitting in terms of the BIC, although it is slightly worse than that of the saturated model, which allows for a saturated association between wives' and husbands' educational achievement $\left(\psi_{i j}^{H W}\right)(-126.4$, results not shown). This result suggests that the association between husbands' and wives' education among university graduates is heterogeneous in terms of their institutions' levels of selectivity, and heterogamy based on their selectivity is distinguishable from those on the main

\footnotetext{
13 The $I D$ is defined as $\sum\left|F_{i j k}-f_{i j k}\right| / 2 n$, where $f_{i j k}$ denotes the observed frequencies of the $(i, j, k)$ cell.
} The $B I C$ is defined as $G^{2}-\log n \times \mathrm{df}$. 
diagonals. Model 1d, which adds crossing parameters, also displays an improved fit, suggesting that the crossing model is also sufficient to capture patterns of assortative mating parsimoniously, although the $B I C$ in this model is slightly worse than the saturated model.

To test Hypothesis 1 and for descriptive purposes, Panel A of Figure 4 presents the parameters estimated by Model $1 \mathrm{~b}$ shown in Table 1. For Model 1b, the parameters of the diagonal cells that represent types of university education (private university and national/public university) tend to be larger $(1.65,3.06)$ than those representing those who did not graduate from university, i.e., high school graduates (1.28). Substantively, for example, the odds ratio of homogamy among national/public university graduates is $21.3(=\exp (3.07))$, implying that these university graduates are 21 times more likely than others to marry spouses with the same type of education. Additionally, if this parameter is read as the strength of homogamy, homogamy is strongest among national/public university graduates (the $95 \%$ confidence interval ranges from 2.74 to 3.40 ), while it is weaker among graduates of private universities (from 1.48 to 1.81 ). Thus, the strength of homogamy among university graduates differs based on their institution's selectivity under the assumption that the parameters are the same across cohorts, which supports the exclusivity hypothesis (Hypothesis 1).

According to crossing parameters estimated by Model 1d shown in Panel B of Figure 4 , as expected, marrying across educational attainment statuses is less likely to occur than marrying within the same educational level. Understandably, the crossing parameter is more negative for marriages between junior college graduates and private university than those between high school graduates and junior college graduates. Meanwhile, the magnitude of crossing parameter for marriages between private university graduates and national/public university graduates is comparable to one between junior college graduates and private university graduates. This result suggests that the difficulty of crossing the education boundary is mainly found between educational levels.

Next, Models 2a is estimated to test Hypothesis 2. Parameters estimated by Model 2a shown in Panel $\mathrm{C}$ of Figure 4 indicate that the relative likelihood is positive for female 
hypergamy and hypogamy, but the former is more likely to occur than the latter net of compositional changes. Specifically, the odds ratio of hypergamy within university graduates is $4.9(=\exp (1.70), 95 \%$ confidence interval ranges from 1.43 to 1.96$)$, while that of hypogamy is $3.3(=\exp (1.18), 95 \%$ confidence interval ranges from 0.85 to 1.50$)$.

[Figure 4 is about here]

\section{Changing assortative mating patterns within university education}

To describe assortative mating trends by education, Model 3a adds parameters to estimate changes in each of the educational assortative mating types articulated in Model 1a. The $B I C$ in this model is lower than that of Model 1a, indicating that the degree of educational homogamy changes over time.

Panel A of Figure 5 presents changes in homogamy for Model 3a. The results indicate that homogamy becomes less likely to occur over time for cohorts than for the reference cohort. This result is consistent with those of previous studies that argued the continuous decline in educational homogamy in Japan (Fujihara and Uchikoshi 2019; Fukuda et al. 2021; Miwa 2007). To examine the trend in educational assortative mating using a more parsimonious model, I also apply a log-multiplicative model (Model 3b). The model fit statistics indicate that the $B I C$ is higher than that of the changing homogamy model. Although the model fit is worse, the logmultiplicative parameters $\beta_{k}^{\mathrm{C}}$ estimated in Model $3 \mathrm{~b}$ present that the association between the husband's and wife's educational attainment in terms of the log-odds ratios declines by $26 \%$ over the three cohorts (results not shown).

To test Hypothesis 3, I examine Models 3c-3e, which add parameters to estimate changes in assortative mating among graduates of each of the educational types. The BIC is lower than 0 across the models but poorer than the reference models (except for the comparison between Model 1c and Model 3d), which suggests that there is no evidence on cohort change in assortative mating; thus, the results should be interpreted for descriptive purpose due to the 
relatively worse fit, although the chi-squared tests of the $G^{2}$ statistic between the hierarchical models (Models $1 \mathrm{~b}$ and $3 \mathrm{c}$ and $1 \mathrm{~d}$ and $3 \mathrm{e}$ ) reveal that the null hypothesis that these models are the same is rejected at the $1 \%$ level of statistical significance. These results, similar to results from Model 3a, suggest that educational homogamy has declined overall but that distinguishing between university graduates by institutional selectivity provides a more nuanced picture of these trends.

Panels B of Figure 5 presents changes in crossing parameters $(3 \mathrm{e})$, the $B I C$ of which is relatively lower than other competing models ( $3 \mathrm{c}$ and $3 \mathrm{~d})$ ). Positive coefficients on the cohort interaction mean more intermarriage in recent cohorts, while negative coefficients indicate less intermarriage. The results show that the difficulty of crossing educational attainment boundaries between private and national/public university graduates increases by $32.0 \%$ across the three cohorts, which is consistent with Hypothesis $3 \mathrm{~b}$. In contrast, crossing boundaries between junior college and private university graduates declines by $12.1 \%$. Interpreting these results in terms of odds of homogamy, homogamy among national/public university graduates increased, which is consistent with Hypothesis $3 \mathrm{a}$ and $3 \mathrm{~b}$.

Last, Model 4 is estimated to test Hypothesis 4, which posits that educational hypergamy within university graduates declines more rapidly than those hypogamy marriages. is Since the model fit statistics of Model 5a is worse than their reference model (Model 2a), I present results for descriptive purpose rather than detecting the best fitting model, but again according to the chi-squared tests of the $G^{2}$ statistic between the hierarchical models we can reject the null hypothesis that these models are the same with a $1 \%$ level of statistical significance. According to Panel C of Figure 5, the cohort interaction with hypergamy is negative while it appears hypogamy trends are stable, consistent with Hypothesis 4. Specifically, educational hypergamy has decreased by $90 \%$ over three marriage cohorts while the decline is limited for educational hypogamy (26\% decline).

[Figure 5 is about here] 


\section{A consideration of other potential explanations for the diverging patterns}

Since the diverging pattern in educational homogamy by college selectivity is a key finding, it is worth considering potential factors that may explain the trend other than the college expansion. Supplementary analyses examined two possibilities (See Appendix Table 2). First, those who are familiar with the literature on American higher education may wonder if the increasing selectivity of the elite college group (Hoxby 2009) may explain the diverging pattern. I estimated ordered logit models separately for men and women, by limiting the sample to three types of university graduates. Results did not find evidence that the selection into selective colleges, measured by father's education, has changed.

Second, it could also be the case that the education-income gradient has changed, something similar to the increasing labor market return to college degree in the United States (Autor 2010; Goldin and Katz 2009). I estimated an OLS regression for logged hourly wage at age 35. I limited the sample to men as women's employment often interrupts with family events. My analysis suggests that returns to selective colleges also did not change over time, which is in line with earlier studies arguing that earnings premium among college graduates has not increased in Japan (Kawaguchi and Mori 2016). Ideally, it would be nice to examine whether women's returns to selective colleges changed, because if it increases, the diverging patterns of homogamy between national/public university graduates and private university graduates may be driven by the increase in women's economic potential that makes them more attractive in the marriage market (from men's perspective). Perhaps more importantly, it could be also the case that the value of women's college education in the marriage market has changed not only because of the increase in the economic return to women's education but because of the growing symmetry in men's and women's economic opportunities, which likely to increase men's emphasis on female spouse's earning role (National Institute of Population and Social Security Research 2017) or change their (stereotypic) views about career-oriented women as a potential marital partner (Woźny 2022). Unfortunately, I am not able to examine directly how such 
changing views on women's economic role or potential affect the pattern of educational homogamy in Japan while paying attention to the growth in within-group variation in terms of selectivity in higher education. Future studies should examine this point.

Third and last, there are good reasons to expect that delayed and fewer marriages among the younger cohorts in Japan (Raymo et al. 2015) may shape assortative mating patterns. For instance, according to Mare (1991)'s time gap hypothesis, delayed marriage is expected to decrease educational homogamy, since the time gap from school graduation to marriage will increase exposure to someone with a different educational background. In that sense, the declining trend in educational homogamy in Japan may reflect delayed marriage. Meanwhile, a classical theory on marriage timing by Oppenheimer (1988) states that delayed marriage may allow singles to speculate their potential spouse's earning potential more accurately, leading to more homogamy. I examined these speculations using an event history technique that allows us to incorporate both the timing of marriage and assortative mating patterns. Results from the analysis which can be found in Appendix, which is fully discussed in Uchikoshi (2018), suggest that the age at marriage does not change the likelihood of college graduates' marrying a similarly educated spouse in Japan. Rather, the declining educational homogamy among college graduates is far more explainable by a relative increase in highly educated women, who tend to prefer marrying similarly educated men (educational homogamy), while the relative supply of these men has declined, resulting in so-called marriage market mismatch (Raymo and Iwasawa 2005). For less marriage, this is likely more critical for homogamy among less-educated individuals, since the declining marriage rate is particularly the case for lower educated, especially men (Fukuda et al. 2020). Although this is not a focus of this paper, future studies should pay attention to how the fewer marriages among less-educated men may or may not change assortative mating patterns.

\section{Discussion}


This paper investigated the patterns of educational assortative mating in Japan over time, focusing on the role of expansion and institutional differentiation in higher education. This study's primary contribution is demonstrating that patterns of educational assortative mating are dependent on how educational categories are measured in the context of rapid educational expansion. First, the results using a finer categorization of university graduates demonstrate that the strength of educational homogamy differs according to the level of institutional selectivity, with a larger likelihood of homogamy among national/public university graduates than among other private university graduates. These findings are consistent with the exclusivity hypothesis (Hypothesis 1). This result adds to our understanding of the heterogeneity in school selectivitybased assortative mating patterns that were obscured in earlier studies. It was also interesting to see that female educational hypergamy is more likely to occur than educational hypogamy even within university graduates, supporting Hypothesis 2 and the notion of strong preference for status hypergamy in Japan (Brinton et al. 2021; Raymo and Iwasawa 2005).

Second, in addition to the initial difference in the strength of homogamy across these groups, there has been a diverging trend in educational homogamy, which generally has declined by approximately $27 \%$ over the three marriage cohorts. Specifically, national/public university graduates have increased their tendency to marry similarly educated spouses, while private university graduates are increasingly less likely to marry these selective university graduates, consistent with the institutional differentiation hypothesis (Hypothesis 3a and 3b). Meanwhile, although this is not expected from the hypotheses, these less selective university graduates marry partners who did not complete college more frequently. This finding echoes the interpretation by Fukuda et al. (2020) that an increase in hypogamy among university-educated women reflects the declining socioeconomic boundaries between less selective universities and other postsecondary institutions. It should be noted, however, the size of change is small $(12 \%$ increase, Panel B of Figure 5).

These results suggest that a relative increase in the number of private university graduates has influenced educational homogamy patterns through multiple ways. One is that the 
relative increase in less selective college graduates decreases the odds of educational homogamy among college graduates (a compositional process). The other is that the increase in odds of homogamy among selective college graduates has mitigated the decline in educational homogamy (a diverging process). Also, aside from theoretical expectations, the slight increase in the likelihood of intermarriage between less selective college graduates and junior college graduates has contributed to the decline in educational homogamy among college graduates. This study was able to reveal such processes by distinguishing college graduates based on the selectivity of the institution they attended.

Last, consistent with Hypothesis 4, results suggest that female educational hypergamy has decreased while this is not necessarily the case for educational hypogamy. This finding provides important insights improving the theoretical framework on the impact of institutional differentiation in higher education, which did not fully consider the role of relative gender difference in higher education expansion. Possibly reflecting the more rapid increase in the share of female students enrolled in private institutions, the opportunity for them to "marry up" has decreased while they are more likely to marry non-university graduates. As such, results of this study imply that it is critical for us to explicitly consider the role of relative gender difference in the rate of expansion in higher education.

However, I acknowledge a number of limitations. First, the classification of selectivity among university graduates in this analysis is crude. For example, there are a few recognizable selective private universities (e.g., Keio or Waseda), whereas earlier work has suggested that the odds of homogamy among these selective private university graduates is lower than that of selective national university graduates (Uchikoshi and Raymo 2021). Still, future studies could provide an improved picture by using a finer selectivity classification, such as one based on school name, rather than the simple national/public-private distinction. Second, since this study used cross-sectional information about spouse pairing patterns, a potential bias was not addressed. In particular, given that older cohorts are more likely to appear to marry homogamously than younger cohorts in cross-sectional data as a result of selective attrition via 
divorce (Tzeng 1992), the current study may have overestimated the decline in educational assortative mating. Third, this study was not able to quantify the contribution of the growth of within-group variation in higher education and assortative mating patterns net of compositional changes to trends in educational homogamy. Future studies should benefit from applying a decomposition method to estimate each contribution (e.g., Leesch and Skopek 2022).

Despite these limitations, the findings in this study provide important insights into how horizontal stratification in higher education impacts educational assortative mating. The perspective on growing institutional heterogeneity within higher education can be applicable to other contexts. Facilitation of higher educational expansion through institutional differentiation has also occurred, for example, in the United States, where the number of for-profit universities increased from the early 1990s until 2010 (National Center for Education Statistics 2019). Studies have argued that graduates from these colleges end up with heavy student loan debt (Deming et al. 2012) and almost no economic benefits (Cellini and Turner 2019), suggesting that the proliferation of these for-profit colleges may have attenuated the increase in educational homogamy among college graduates (Schwartz and Mare 2005). Thus, future research should also benefit from examining whether the growth in institutional heterogeneity within higher education is associated with changes in educational assortative mating in these countries.

To conclude, the bridging of horizontal stratification and assortative mating, two determinants of social stratification in contemporary societies, provides important insights into our overarching questions about social stratification. As a potential determinant of increasing economic inequality, assortative mating has drawn enormous attention (Breen and Andersen 2012; Breen and Salazar 2010; Esping-Andersen 2007; Schwartz 2010; Shen 2021; Torche 2010), although evidence for its actual influence on inequality is mixed (Schwartz 2013). This mixed evidence might be due to an inappropriate categorization of educational attainment. For example, educational homogamy may increase for a particular subgroup (e.g., selective university graduates), while the opposite might be true for other subgroups (e.g., nonselective university graduates). If this is the case, these groups likely impact growing income inequality 
differently. Therefore, my results suggest that close attention should be paid to the important and growing heterogeneity of institutional characteristics that has been obscured in earlier studies to understand the impact of educational assortative mating on economic inequality.

\section{References}

Andrade, S.B. and Thomsen, J. (2019). Educational assortative mating: a micro-educational approach. The British Journal of Sociology 70(4):1245-1275. doi:10.1111/14684446.12488.

Arum, R., Gamoran, A., and Shavit, Y. (2007). More inclusion than diversion: expansion, differentiation, and market structure in higher education. In: Shavit, Y., Arum, R. and Gamoran, A. (eds.). Stratification in Higher Education: A Comparative Study. Stanford: Stanford University Press: 1-35.

Arum, R., Roksa, J., and Budig, M.J. (2008). The romance of college attendance: Higher education stratification and mate selection. Research in Social Stratification and Mobility 26(2):107-121. doi:10.1016/j.rssm.2008.02.003.

Arum, R. and Roksa, J. (2014). Aspiring Adults Adrift: Tentative Transitions of College Graduates. University of Chicago Press.

Autor, D. (2010). The Polarization of Job Opportunities in the U.S. Labor Market. (Joint report for the Center for American Progress and the Hamilton Project). Retrieved from https://economics.mit.edu/files/5554.

Blau, P.M. and Schwartz, J.E. (1984). Crosscutting Social Circles: Testing a Macrostructural Theory of Intergroup Relations. Academic Press.

Blossfeld, H.-P. (2009). Educational Assortative Marriage in Comparative Perspective. Annual Review of Sociology 35(1):513-530. doi:10.1146/annurev-soc-070308-115913. 
Blossfeld, H.-P. and Timm, A. (2003). Who Marries Whom? Springer Science \& Business Media. Educational Systems as Marriage Markets in Modern Societies.

Bouchet-Valat, M. (2014). Les évolutions de l'homogamie de diplôme, de classe et d'origine sociales en France (1969-2011) : ouverture d'ensemble, repli des élites. Revue française de sociologie 55(3):459. doi:10.3917/rfs.553.0459.

Breen, R. and Andersen, S.H. (2012). Educational Assortative Mating and Income Inequality in Denmark. Demography 49(3):867-887. doi:10.1007/s13524-012-0111-2.

Breen, R. and Salazar, L. (2010). Has Increased Women's Educational Attainment Led to Greater Earnings Inequality in the United Kingdom? A Multivariate Decomposition Analysis. European Sociological Review 26(2):143-157. doi:10.1093/esr/jcp011.

Brinton, M.C., Mun, E., and Hertog, E. (2021). Singlehood in contemporary Japan: Rating, dating, and waiting for a good match. Demographic Research 44:239-276. doi:10.4054/DemRes.2021.44.10.

Burtless, G. (1999). Effects of growing wage disparities and changing family composition on the US income distribution. European Economic Review 43:853-865.

Cellini, S.R. and Turner, N. (2019). Gainfully Employed?: Assessing the Employment and Earnings of For-Profit College Students Using Administrative Data. Journal of Human Resources 54(2):342-370. doi:10.3368/jhr.54.2.1016.8302R1.

Collins, R. (1979). The Credential Society: An Historical Sociology of Education and Stratification. Academic Press.

Deming, D.J., Goldin, C., and Katz, L.F. (2012). The For-Profit Postsecondary School Sector: Nimble Critters or Agile Predators? Journal of Economic Perspectives 26(1):139-164. doi:10.1257/jep.26.1.139. 
DiPrete, T.A. and Buchmann, C. (2013). The Rise of Women: The Growing Gender Gap in Education and What It Means for American Schools. Russell Sage Foundation.

Edwards, L.N. and Pasquale, M.K. (2003). Women's Higher Education in Japan: Family Background, Economic Factors, and the Equal Employment Opportunity. Journal of the Japanese and International Economies 17(1):1-32. doi:10.1016/S0889-1583(03)00004-2.

Esping-Andersen, G. (2007). Sociological Explanations of Changing Income Distributions. American Behavioral Scientist 50(5):639-658.

Esteve, A., Garcia-Roman, J., and Permanyer, I. (2012). The Gender-Gap Reversal in Education and Its Effect on Union Formation: The End of Hypergamy? Population and Development Review 38(3):535-546. doi:10.1111/j.1728-4457.2012.00515.x.

Esteve, A., Schwartz, C.R., Van Bavel, J., Permanyer, I., Klesment, M., and Garcia-Roman, J. (2016). The End of Hypergamy: Global Trends and Implications. Population and Development Review 42(4):615-625.

Feng, A. J., (2022). Revisiting Horizontal Stratification in Higher Education: College Prestige Hierarchy and Educational Assortative Mating in China. Demography. (Advance publication)

Fujihara, S. and Uchikoshi, F. (2019). Declining association with persistent gender asymmetric structure: patterns and trends in educational assortative marriage in Japan, 1950-1979. Research in Social Stratification and Mobility 60:66-77. doi:10.1016/j.rssm.2018.12.001.

Fukuda, S., Raymo, J.M., and Yoda, S. (2020). Revisiting the Educational Gradient in Marriage in Japan. Journal of Marriage and Family 82(4):1378-1396. doi:10.1111/jomf.12648. 
Fukuda, S., Yoda, S., and Mogi, R. (2021). Educational Assortative Mating in Japan: Evidence from the 1980-2010 Census. Jinko Mondai Kenkyu (Journal of Population Research):(in Japanese).

Gerber, T.P. and Cheung, S.Y. (2008). Horizontal Stratification in Postsecondary Education: Forms, Explanations, and Implications. Annual Review of Sociology 34(1):299-318. doi:10.1146/annurev.soc.34.040507.134604.

Goldin, C.D. and Katz, L.F. (2009). The Race between Education and Technology. Harvard University Press.

Han, H. (2010). Trends in Educational Assortative Marriage in China from 1970 to 2000. Demographic Research 22:733-770. doi:10.4054/DemRes.2010.22.24.

Hersch, J. (2013). Opting out among women with elite education. Review of Economics of the Household 11(4):469-506. doi:10.1007/s11150-013-9199-4.

Hout, M. and DiPrete, T.A. (2006). What We Have Learned: RC28's Contributions to Knowledge about Social Stratification. Research in Social Stratification and Mobility 24(1):1-20. doi:10.1016/j.rssm.2005.10.001.

Hoxby, C.M. (2009). The Changing Selectivity of American Colleges. Journal of Economic Perspectives 23(4):95-118.

$\mathrm{Hu}$, A. and Qian, Z. (2015). Educational homogamy and earnings inequality of married couples: Urban China, 1988-2007. Research in Social Stratification and Mobility 40:1-15. doi:10.1016/j.rssm.2015.01.004.

Ishida, H. (1998). Educational credentials and labour-market entry outcomes in Japan. In: Shavit, Y. and Muller, W. (eds.). From School to Work: A Comparative Study of Educational Qualifications and Occupational Destinations. Clarendon Press: 287-309. 
Ishida, H. (2007). Japan: Educational Expansion and Inequality in Access to Higher Education. In: Shavit, Y., Arum, R. and Gamoran, A. (eds.). Stratification in Higher Education: A Comparative Study. Stanford: Stanford University Press: 63-86.

Ishii, K. and Nozaki, H. (2014). Constructing Longitudinal and Cross-sectional Weights in KHPS and JHPS. Mita Business Review 57(4): 123-145. (in Japanese)

Kalmijn, M. (1998). Intermarriage and Homogamy: Causes, Patterns, Trends. Annual Review of Sociology:395-421.

Katrňák, T. and Manea, B.C. (2020). Change in prevalence or preference? Trends in Educational Homogamy in Six European Countries in a Time of Educational Expansion. Social Science Research (Online first).

Kawaguchi, D. and Mori, Y. (2016). Why has wage inequality evolved so differently between Japan and the US? The role of the supply of college-educated workers. Economics of Education Review 52:29-50. doi:10.1016/j.econedurev.2016.01.002.

Leesch, J. and Skopek, J. (2022). Decomposing Trends in Educational Homogamy and Heterogamy: The Case of Ireland. Paper presented at the RC28 Spring Meeting at London School of Economics, London, April 23.

Lichter, D.T. and Qian, Z. (2019). The Study of Assortative Mating: Theory, Data, and Analysis. In: Schoen, R. (ed.). Analytical Family Demography. Cham: Springer International Publishing: 303-337. doi:10.1007/978-3-319-93227-9_13.

Logan, J.A. (1996). Rules of Access and Shifts in Demand: A Comparison of Log-Linear and Two-Sided Logit Models. Social Science Research 25(2):174-199. doi:10.1006/ssre.1996.0008. 
Lucas, S.R. (2001). Effectively Maintained Inequality: Education Transitions, Track Mobility, and Social Background Effects. American Journal of Sociology 106(6):1642-1690.

Mare, R.D. (1991). Five Decades of Educational Assortative Mating. American Sociological Review 56(1):15-32.

Ministry of Education, Culture Sports, Science and Technology (MEXT) (2019). Statistical Abstract.

Miwa, S. (2007). Long-term Trends in Status Homogamy. In: Sato, Y. (ed.). Deciphering Stratification and Inequality. Trans Pacific Press: 140-160.

Naoi, M. (2006). Household housing movements and sample attrition. Keio University Market Quality Research Project Discussion Paper Series.

National Center for Education Statistics (2019). The Condition of Education 2019.

National Institute of Population and Social Security Research (2017). Marriage and childbirth in Japan: The Fifteenth Japanese National Fertility Survey, 2015. Tokyo: National Institute of Population and Social Security Research. [in Japanese]

Oppenheimer, V.K. (1988). A Theory of Marriage Timing. American Journal of Sociology 94(3):563-591.

Parkin, F. (1971). Class Inequality and Political Order. University of California Press.

Raftery, A.E. (1995). Bayesian Model Selection in Social Research. Sociological Methodology 25:111-163. doi: $10.2307 / 271063$.

Rauscher, E. (2015). Effects of Early U.S. Compulsory Schooling Laws on Educational Assortative Mating: The Importance of Context. Demography 52(4):1219-1242. doi: $10.1007 / \mathrm{s} 13524-015-0402-5$. 
Ravazzini, L., Kuhn, U., and Suter, C. (2017). Do Opposites Attract? Educational Assortative Mating and Dynamics of Wage Homogamy in Switzerland, 1992-2014. Swiss Journal of Sociology 43(3):567-586. doi:10.1515/sjs-2017-0028.

Raymo, J.M. and Iwasawa, M. (2005). Marriage Market Mismatches in Japan: An Alternative View of the Relationship Between Women's Education and Marriage. American Sociological Review 70(5):801-822. doi:https://doi.org/10.1177/000312240507000504.

Raymo, J.M., Park, H., Xie, Y., and Yeung, W.J. (2015). Marriage and Family in East Asia: Continuity and Change. Annual Review of Sociology 41(1):471-492. doi:10.1146/annurevsoc-073014-112428.

Roksa, J., Grodsky, E., Arum, R., and Gamoran, A. (2007). United States: Changes in Higher Education and Social Stratification. In: Shavit, Y., Arum, R. and Gamoran, A. (eds.). Stratification in Higher Education: A Comparative Study. Stanford: Stanford University Press: 165-191.

Sakaguchi, N. (2014). Attrition of Respondents from Japanese Panel Survey of Consumers. Japanese Journal of Research on Household Economics 104: 34-41. (in Japanese)

Schwartz, C.R. (2010). Earnings Inequality and the Changing Association between Spouses' Earnings. American Journal of Sociology 115(5):1524-1557. doi:https://doi.org/10.1086/651373.

Schwartz, C.R. (2013). Trends and Variation in Assortative Mating: Causes and Consequences. Annual Review of Sociology 39(1):451-470. doi:10.1146/annurev-soc-071312-145544. Schwartz, C.R. and Mare, R.D. (2005). Trends in Educational Assortative Marriage from 1940 to 2003. Demography 42(4):621-646. 
Shen, Y. (2021). The Nonlinear Linkage between Earnings Homogamy and Earnings Inequality Among Married Couples. Demography 58 (2): 527-550.

Smits, J. (2003). Social Closure among The Higher Educated: Trends in Educational Homogamy in 55 Countries. Social Science Research 32(2):251-277.

Smits, J. and Park, H. (2009). Five decades of educational assortative mating in 10 East Asian societies. Social Forces 88(1):227-255.

Torche, F. (2010). Educational Assortative Mating and Economic Inequality: A Comparative Analysis of Three Latin American Countries. Demography 47(2):481-502.

Toyonaga, K. (2018). Effects of College Selectivity and College Major on First Job Attainment among Male and Female University Graduates. Japanese Sociological Review 69(2):162178 (in Japanese).

Tzeng, J.M. (1992). The Effects of Socioeconomic Heterogamy and Changes on Marital Dissolution for First Marriages. Journal of Marriage and Family 54(3):609-619.

Uchikoshi, F. (2018). Assortative Mating in the Age of Marriage Decline. Sociological Theory and Method (Riron to Hoho) 33(1): 15-31. doi:10.11218/ojjams.33.15.

Uchikoshi, F. and Raymo, J.M. (2021). Educational Assortative Mating in Japan: Insights into Social Change and Stratification. Springer.

Van Bavel, J., Schwartz, C.R., and Esteve, A. (2018). The Reversal of the Gender Gap in Education and Its Consequences for Family Life. Annual Review of Sociology 44(1):341360. doi:10.1146/annurev-soc-073117-041215.

Woźny, Anna. (2022). Herbivorous Men, Carnivorous Women: Doing Masculinity and Femininity in Japanese "Marriage Hunting” Signs: Journal of Women in Culture and Society 47 (3), 715-740. 
Wong, R.S.-K. (2003). To See or Not To See: Another Look at Research on Temporal Trends and Cross-National Differences in Educational Homogamy. Taiwanese Journal of Sociology 31:45-88.

Xie, Y. (1992). The Log-Multiplicative Layer Effect Model for Comparing Mobility Tables. American Sociological Review 57(3):380-395.

Yonezawa, A., Nakatsui, I., and Kobayashi, T. (2002). University Rankings in Japan. Higher Education in Europe 27:373-382. 
Table 1 Goodness-of-fit statistics for the models

\begin{tabular}{|c|c|c|c|c|c|}
\hline \multirow{2}{*}{ Models } & & \multicolumn{4}{|c|}{ Goodness of fit of models } \\
\hline & & $G^{2}$ & df & $I D$ & $B I C$ \\
\hline $0 \quad[\mathrm{HC} \mathrm{WC}]$ & Conditional independence & 1793.2 & 27 & $19.1 \%$ & 1551.9 \\
\hline \multicolumn{6}{|l|}{ Models for Hypothesis 1} \\
\hline 1a $\quad\left[\mathrm{HC} \mathrm{WC} \delta^{\mathrm{HW}}\right]$ & Homogamy (matrix 1) & 219.7 & 25 & $4.8 \%$ & -3.7 \\
\hline $1 \mathrm{~b} \quad\left[\mathrm{HC} \mathrm{WC} \delta^{\mathrm{HW}}\right]$ & Homogamy (matrix 2) & 91.8 & 23 & $3.7 \%$ & -113.7 \\
\hline $1 \mathrm{c} \quad\left[\mathrm{HC} \mathrm{WC} \delta^{\mathrm{HW}}\right]$ & Homogamy (matrix 3) & 257.7 & 23 & $4.3 \%$ & 52.2 \\
\hline $1 \mathrm{~d} \quad\left[\mathrm{HC} \mathrm{WC} \gamma^{\mathrm{HW}}\right]$ & Crossing & 93.8 & 24 & $3.8 \%$ & -120.7 \\
\hline \multicolumn{6}{|l|}{ Models for Hypothesis 2} \\
\hline $2 \quad\left[\mathrm{HC} \mathrm{WC} \delta^{\mathrm{HW}}\right]$ & Homogamy (matrix 4) & 85.8 & 22 & $3.7 \%$ & -110.8 \\
\hline \multicolumn{6}{|c|}{ Models for describing assortative mating trends } \\
\hline 3a $\quad\left[\mathrm{HC} \mathrm{WC} \mathrm{HW} \delta^{\mathrm{HWC}}\right]$ & Changing homogamy (matrix 1) & 23.5 & 14 & $1.0 \%$ & -101.6 \\
\hline $3 \mathrm{~b} \quad\left[\mathrm{HC} \mathrm{WC} \delta^{\mathrm{HW}} \beta^{\mathrm{C}}\right]$ & Homogamy, LM (matrix 1) & 206.6 & 23 & $4.2 \%$ & 1.1 \\
\hline \multicolumn{6}{|l|}{ Models for Hypothesis 3} \\
\hline $3 \mathrm{c} \quad\left[\mathrm{HC} \mathrm{WC} \mathrm{HW} \delta^{\mathrm{HWC}}\right]$ & Changing homogamy (matrix 2) & 11.8 & 10 & $0.6 \%$ & -77.6 \\
\hline $3 \mathrm{~d} \quad\left[\mathrm{HC} \mathrm{WC} \mathrm{HW} \delta^{\mathrm{HWC}}\right]$ & Changing homogamy (matrix 3) & 14.0 & 10 & $0.6 \%$ & -75.4 \\
\hline 3e $\quad\left[\mathrm{HC} \mathrm{WC} \mathrm{HW} \gamma^{\mathrm{HWC}}\right]$ & Changing crossing & 16.6 & 12 & $0.8 \%$ & -90.7 \\
\hline \multicolumn{6}{|l|}{ Models for Hypothesis 4} \\
\hline $4 \quad\left[\mathrm{HC} \mathrm{WC} \mathrm{HW} \delta^{\mathrm{HWC}}\right]$ & Changing homogamy (matrix 4) & 9.5 & 8 & $0.5 \%$ & -62.0 \\
\hline
\end{tabular}




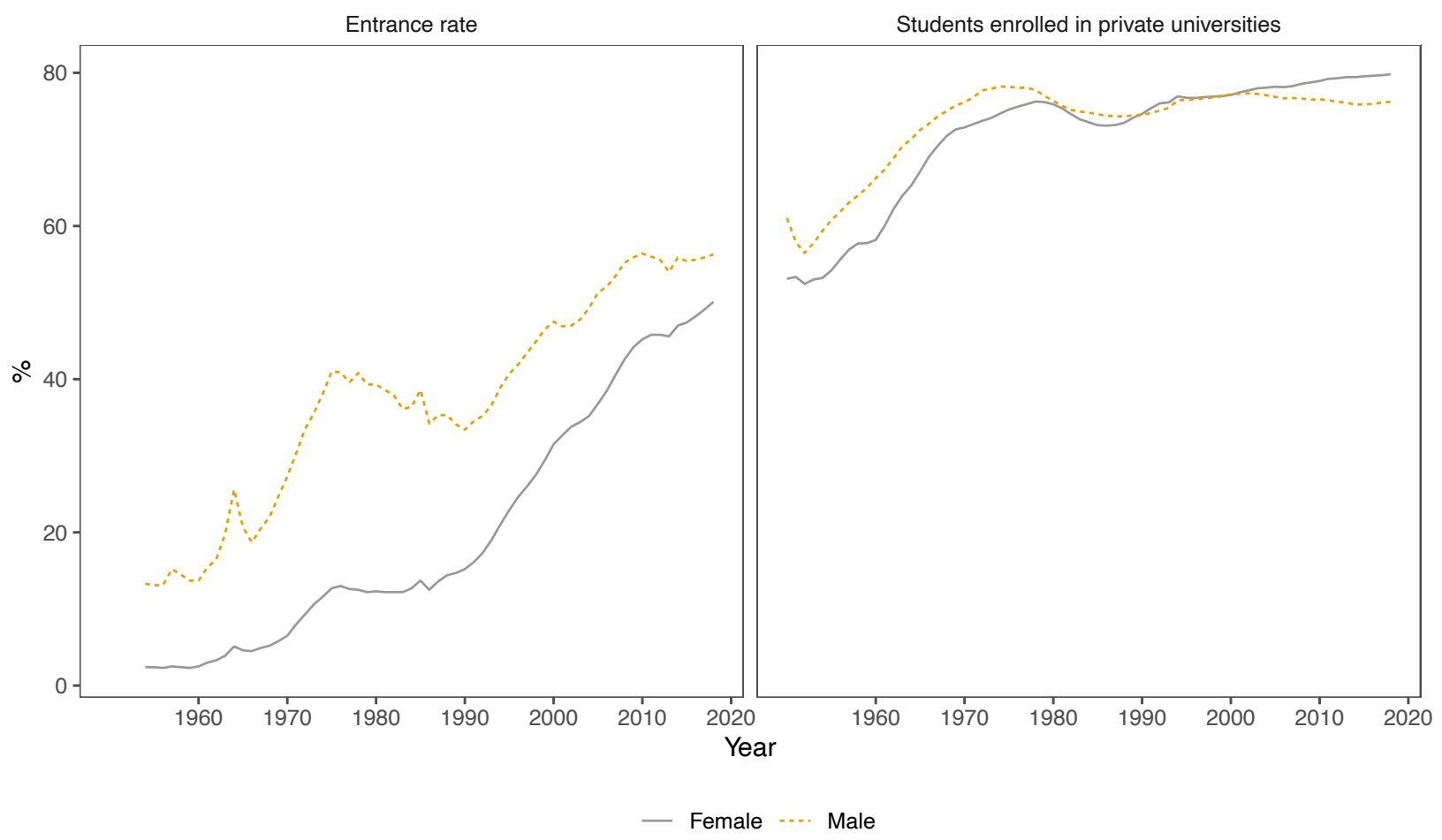

Source: School Basic Survey, Ministry of Education, Culture, Sports, Science and Technology Note: Entrance rate is calculated by total number of enrolled students out of high school graduates Figure 1 Trends in university enrollment in Japan 

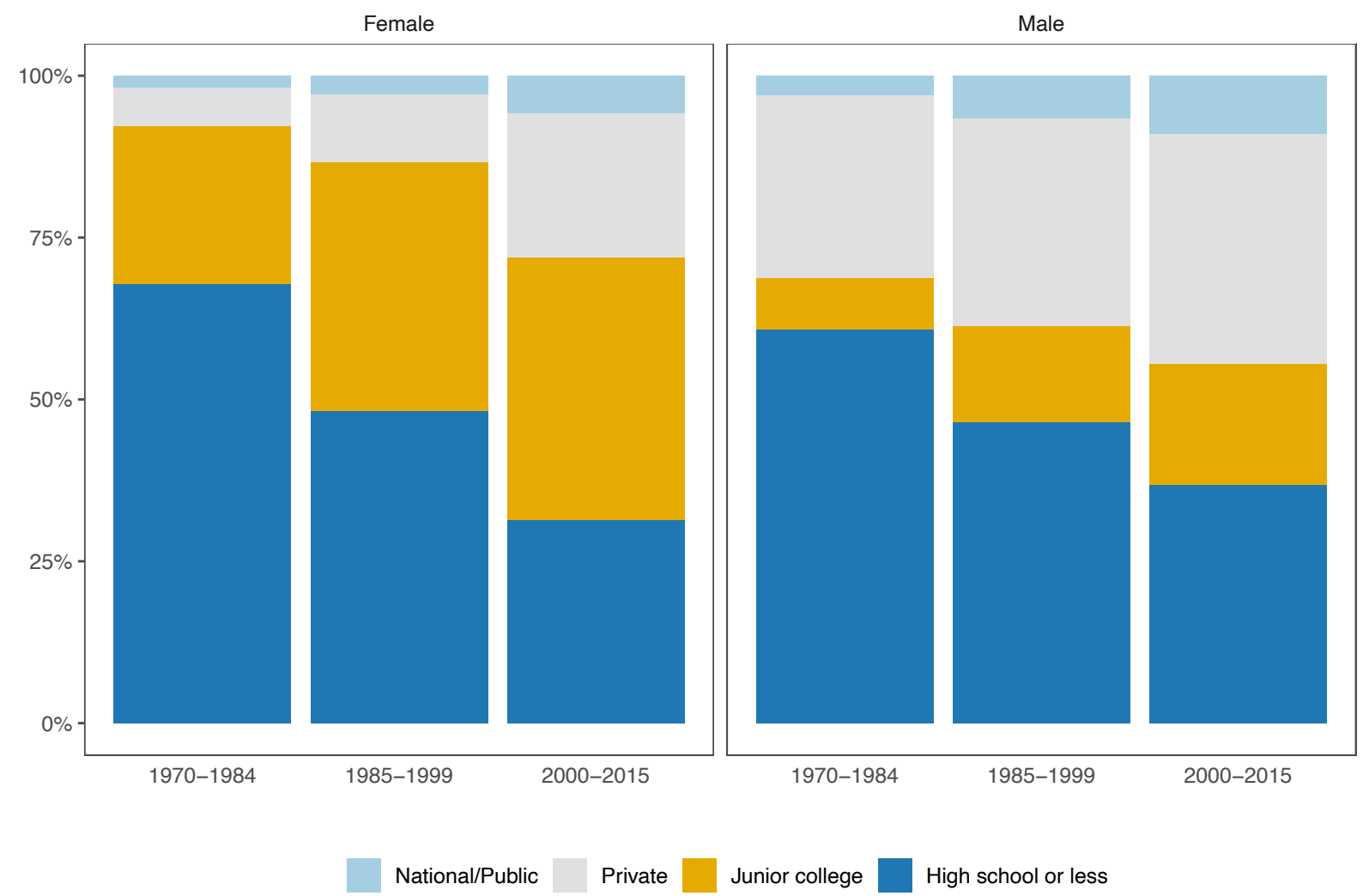

Figure 2 Respondents' educational attainment by gender and marriage cohort
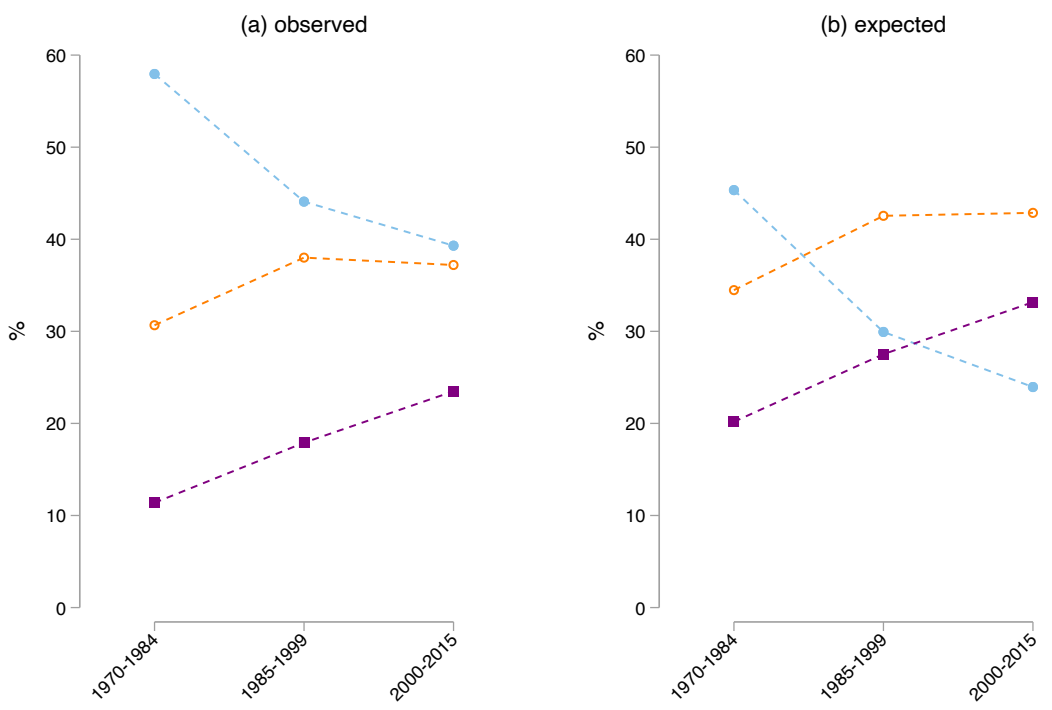

-. Homogamy

-. Hypergamy

-. Hypogamy

Figure 3 Observed and expected distributions of homogamy, hypergamy, and hypogamy by marriage cohort 

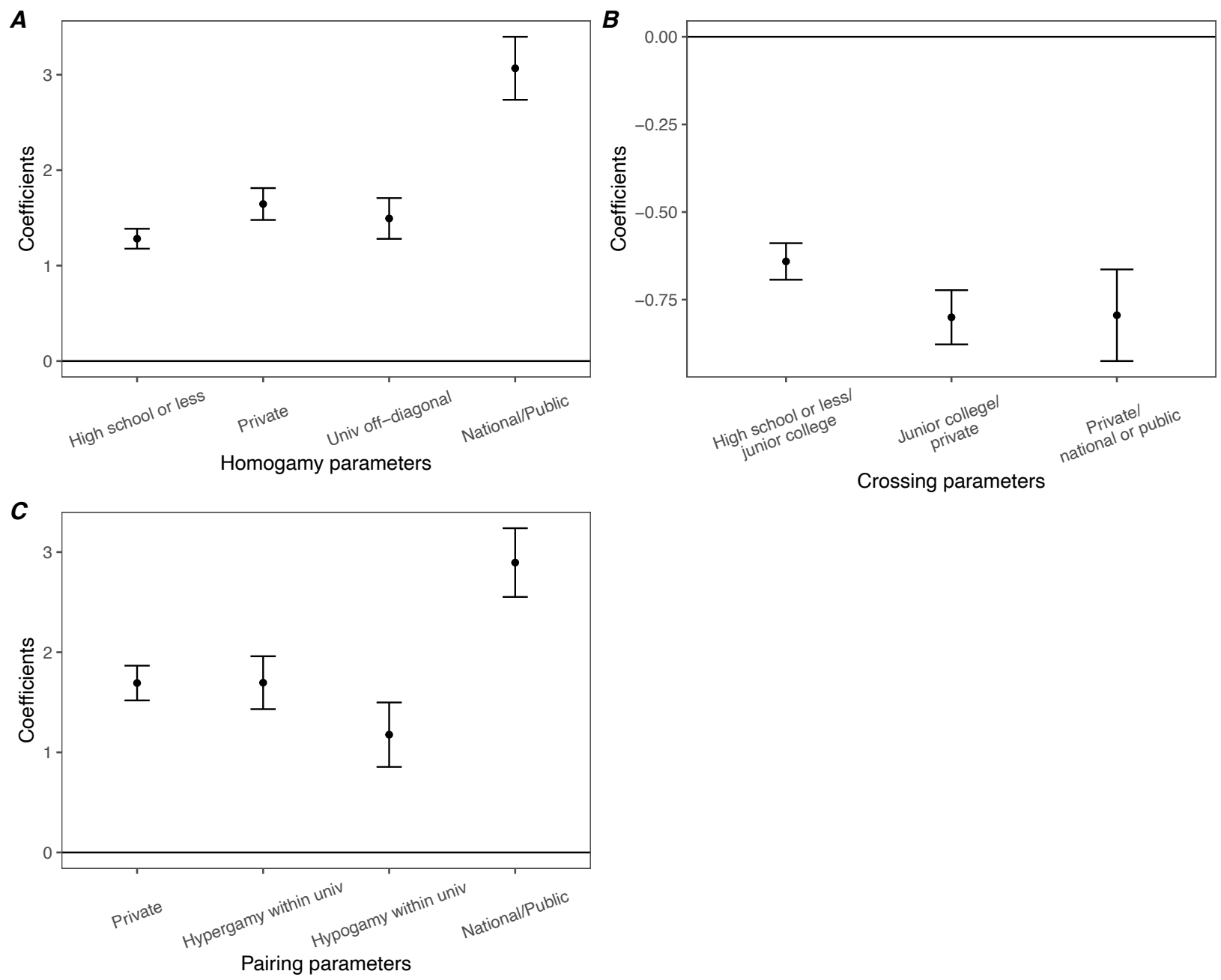

Figure 4 Parameters of association between husbands' and wives' educational attainment (A: estimated by Model 1b; B: estimated by Model 1d; C: estimated by Model 2a)

Note: Error bars indicate the $95 \%$ confidence intervals. 

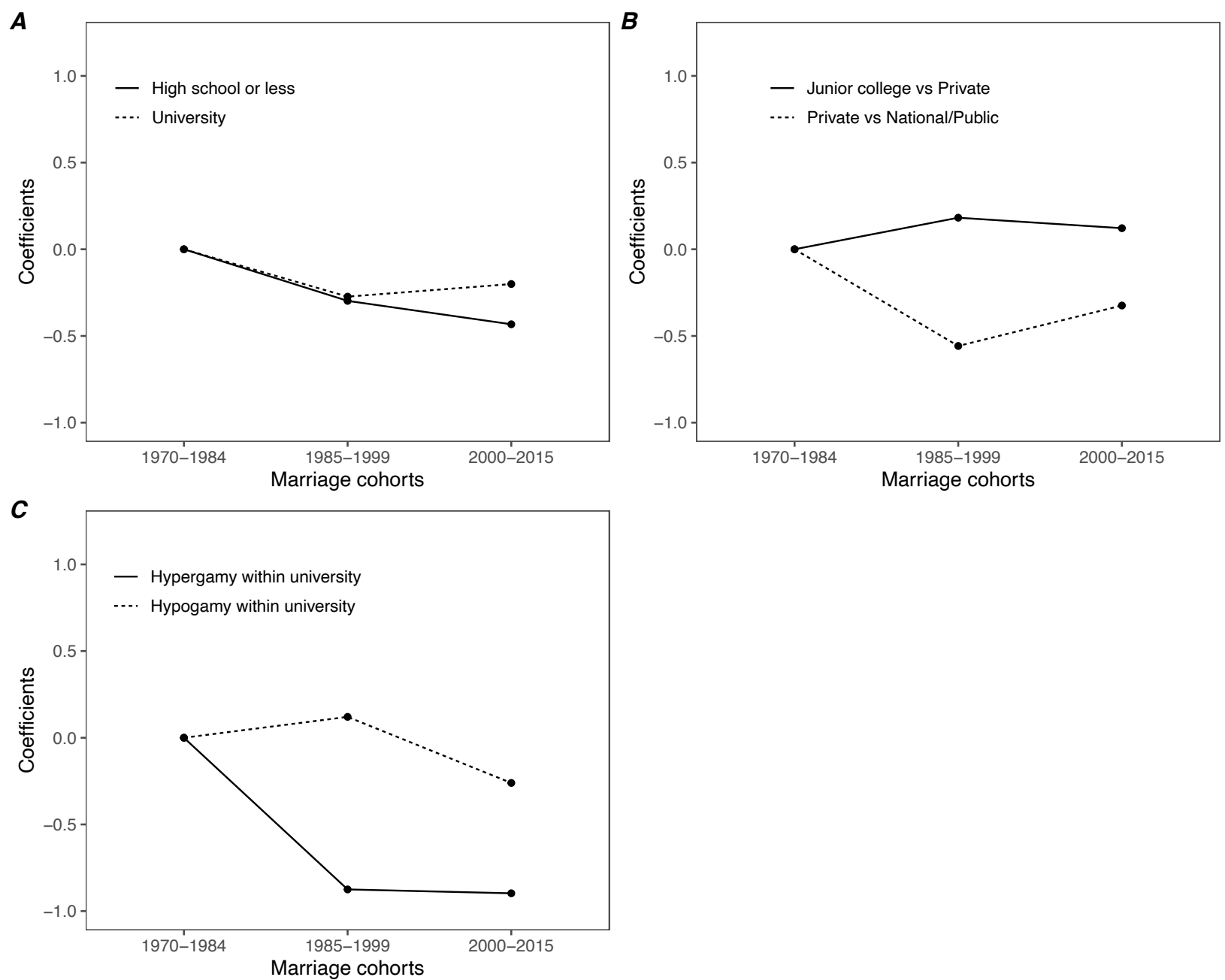

Figure 5 Changes in the homogamy and crossing parameters by marriage cohort (A: estimated by Model 3a; B: estimated by Model 4d; C: estimated by Model 5a)

Note: Coefficients on the $\mathrm{Y}$ axis show the degree to which educational assortative mating varies by marriage cohort, which are expressed as $\delta_{i j k}^{H W C}$ in the equations. 